- célibe Ruth- esas dos frases que emplea como epígrafes llenos de desencanto, lo mismo que una cita de Chesterton, y para sumergirse en la meditación, con precoz amargura.

Mas el ritmo joven de su sangre, que la hizo pasar del teatro - poesía en acción- a lecturas y escrituras - no siempre sagradas-, palpita rebelándose en los endecasílabos, heptasílabos, octosílabos y tetrasílabos, que se suceden combinados en sonetos, liras, nuevas estrofas.

Es sobre todo en las décimas iniciales, que se deslizan con engañoso, aparentemente fácil impulso -a veces calderoniano-, donde se ve mejor ubicada la poesía de Guadalupe Amor, en este libro.

Sabe formar, de una sola pieza, los eslabones de las espinelas, que no se unen forzosamente en cadena estable ni exigen unidad, al ir sorteando las sirtes de arcaicas filosofías, en ágil paso de la física a la metafísica.

$\mathrm{Si}$ a ratos nos alarma su prematuro escepticismo, luego nos tranquiliza Guadalupe Amor, al confiarnos que halló unas imágenes, en matutina pesca milagrosa, mientras se asomaba, con actitud muy femenina, al sereno estanque de su espejo.

Así alternan, en la plaquette, máscara y rostro.

Poesía hecha a la vez de vigilante inquietud y decantada concentración, esta de Guadalupe Amor, va de lo fugaz a lo eterno, al enfocar el tema elegido - polvo, germen de mundos y sudario de civilizacionesdesde diversos ángulos, en los que ella tuvo el capricho y la audacia de situarse.

Al final, Guadalupe Amor aun nos of rece una singular teoría, apenas insinuada en $L a$ visitación al diablo, que cierra - tan mexicana, ingeniosamente- el poema realizado con pulcra tipografía.

Francisco Monterde

Julio Jiménez Rueda, Historia de la cultura en México. El Virreinato.Editorial Cultura, T. G., S. A. México, 1950.

Muy pronto cuatro siglos cumplidos van a medir la distancia temporal que nos separa de la fundación y el establecimiento de la Universidad mexicana, y como el hombre está tejido de la substancia del tiempo, es criatura de historia y por ende muy dado a las conmemoraciones. Es así, pues, que cual más, cual menos, todos los de acá que par algún motivo tenemos arrimo a la vieja casa de estudios nos aprestamos a engalonar la fecha. Primogénito de esta codicia es el libro recentisimo que, 
con título de Historia de la cultura en México, acaba de publicar don Julio Jiménez Rueda, para utilidad y solaz de los leyentes. $Y$ pues que por razones de fortuna y circunstancia he sido, así lo creo, el primer peregrino de este nuevo camino que conduce a nuestro pasado, tócame la grata tarea de ser, así lo espero, el primero en su reclamo.

Una inicial advertencia es urgente: el autor ha constreñido su pluma a la Nueva España con ánimo, pienso, de proseguir en el empeño con un volumen primero que se retrotraiga a lo precortesiano y con otro tercero que se alargue al México independiente. Este volumen que ahora nos ocupa será, pues, a la larga, el segundo de una obra de mayor alzada y más completa. No incurramos, sin embargo, en un malentendido: este libro de Jiménez Rueda sobre la historia de la cultura de nuestro pasado colonial se sostiene por sí sólo, porque es obra que satisface cumplidamente el propósito que le dió la vida, sin necesidad del concurso de sus futuros hermanos. $Y$ en efecto veamos en seguida el inventario en grueso de su contenido, como justificación de nuestro aserto.

Tras una breve introducción donde el autor declara la meta de sus desvelos, pasamos a un primer capítulo - "Prolegómenos de la colonización"- que es el cuadro del mundo histórico en que se despliega la empresa indiana. La conquista y la colonización de América por los castellanos es un voluminoso suceso cuyo significado nos elude si no lo contemplamos a la luz de las aspiraciones renacentistas que lo animan, pero al mismo tiempo a la sombra del legado medieval que lo vincula a la secular tradición católico-imperialista de la cual es España tan principal heredera y podríamos decir, albacea de su supervivencia. Y así, atenciiendo el autor a este doble reclamo, dedica las iniciales páginas de su libro a fijar el tema sobre la cruz que forman ambas tendencias.

Preparado ya el lector a la aventura, que en todos sus detalles y accidentes mostrará siempre el dualismo de su génesis, podrá proseguir sin temor de extravío el largo camino de tres siglos que ocupa nuestra vida colonial. Once capitulos más son las otras tantas estaciones de oteo que el autor le ofrece para considerar desde ellas los diversos y más fundamentales aspectos de esa vida. Viene primero una inspección del territorio y de su población; pasamos en seguida a mirar cuáles fueron y cuáles las instituciones sociales y políticas que dieron estructura a la Nueva España. Las relaciones entre 'Iglesia y Estado constituyen el nuevo paso, cuestión de suma importancia, no sólo por referirse a uno de los ejes capitales de aquel modo de vida y cultura, sino porque en su estudio encontramos agazapado el dualismo inicial de que ya hablamos, germen de disolución del Imperio. En efecto, desde temprana hora el autor nos hace asistir a la disidencia que turbó la presupuesta hermandad de catedral y palacio, sorda y profunda pugna que, por debajo de engañosa 
apariencia, mina los cimientos del edificio colonial, para estallar a flor de historia en las postrimerías del siglo xviI y para dejarle a la República ese legado de interna disidencia que, como dice el autor, llena toda la historia del siglo xxx mexicano.

El capítulo siguiente, el sexto, atiende a los problemas de la economía e industria coloniales, sin incurrir en el frecuente olvido del significado que tuvo y aún tiene para nuestra vida el mercado de indios, el tiangues, tan celebrado por la pluma de cronistas y turistas, de propios y extraños. Aquí hacemos un alto. Detrás de nosotros ha quedado el cuadro institucional de la Nueva España; en lo que falta vamos a penetrar en la esfera de las ideas, las letras, el arte, la educación y las costumbres, buenas y malas, el cuadro cultural, en suma, del viejo virreinato. Sendos capítulos dedica el autor a los temas enunciados. Bajo el título de "Ideario de la época" examinemos en su compañia el humanismo mexicano; la huella que acá nos dejó Erasmo; el barroco y la Contrarreforma, y por último, la Ilustración y la modernidad tan teñida de preocupación científica. En "Las letras", encontramos, entre otras-hermanas, la historiografía, la lírica, la mística, el teatro y el periodismo, con un apartado final dedicado al lenguaje y a la paremiología. El "Arte" comprende la plástica y la música coloniales; la "Enseñanza" nos of rece el panorama general de las escuelas, de los colegios y de la Universidad, y en el capítulo de "Vida y costumbres" asistimos a ceremonias civiles y religiosas, a fiestas y a los públicos espectáculos en que los coloniales, nuestros padres distraían sus ocios. No omite el autor, y hace bien, dedicar un último apartado al arte culinario, una de las cumbres, a no dudarlo, de nuestra cultura.

Una honda y compleja crisis acarrea la ruina del Virreinato; el viejo encono del criollo rompe el dique secular a sus anhelos, y estamos ya a la puerta donde, a punto de dar el grito, nos esperan Hidalgo y su bandera. Aquí, pues, cerramos el libro, no menos ricos que agradecidos por el botín de Nueva España que traemos a cuestas.

Toda obra lleva un propósito que la da vida y sentido, y su' bondad estriba en la manera en que el autor lo cumple. ¿Cuál, entonces, es el que anima a este libro? Expresamente nos lo dice Jiménez Rueda. Se trata de un ensayo de integración de los conceptos dispersos hasta ahora sobre todos los aspectos de la vida mexicana colonial. No es, sin embargo, un libro polémico que aspire a dirimir controversias, ni en él se propone tesis alguna. Tampoco pretende agotar temas; "ni ir más allá de lo que hasta ahora han explicado los especialistas". Se trata, pues, de un panorama general sintético que tiene por objeto presentar de un golpe de vista nuestro pasado inmediato. Creo, entonces, que el autor 
ha satisfecho cumplidamente su intento, y al hacer esto, el autor ha venido a llenar una laguna en nuestra producción historiográfica que hace mucho precisaba llenar. Difícilmente pueden encontrar el estudiante y el estudioso una mejor manera para introducirse al conocimiento de la cultura de la Nueva España, que no sea con la lectura de este reciente libro del señor Jiménez Rueda.

\section{EDMUNDO O'GORMAN}

Luisita Agurlera Patiño, El panameño visto a través de su lenguaje.Panamá, R. de P., Ferguson \& Ferguson, s. f. 415 pp.

Entre los libros que me llevé de Panamá, tras un grato instante de acercamiento al generoso e inquieto espíritu panameño, figura el valioso trabajo de la profesora Luisita Aguilera Patiño, sobre las peculiaridades del castellano hablado en el istmo. No cabe duda que esta obra está destinada a despertar vivamente el interés de los americanistas, pues el papel de Panamá -importantísimo por razones históricas y geográficasen la evolución de la lengua española en América, ha sido muy poco estudiado hasta ahora. Es Panamá, por ejemplo, casi el único país hispanoamericano que todavía no ha dado a conocer su intimidad lingüística por medio de un diccionario de regionalismos, lo que crea un grave obstáculo para la plena comprensión de su literatura en el extranjero.

El libro de la profesora Aguilera es otra manifestación del gran esfuerzo intelectual que están haciendo los panameños hoy en día, para ir al encuentro de lo suyo. Representa el mismo anhelo de destacar los elementos y valores fundamentales de la civilización panameña que hallamos en los eruditos tratados de Juan Antonio Susto y Rodrigo Miró, - bien, dentro de lo puramente literario, en las obras de casi todos los jóvenes que hoy son una alta promesa para el porvenir de las letras en Panamá.

En el fondo este anhelo de auto-identificación significa una reacción contra el extranjerismo, más fuerte y peligroso en Panamá que en cualquier otro país de Hispanoamérica, a no ser la isla de Puerto Rico. Los amantes de la cultura humanística - seamos quienes fuéremos- debemos mirar con simpatía y seguir con hondo interés el desarrollo de ese movimiento en defensa de lo panameño, porque si un país olvida o malogra lo que tiene de inconfundible, de profunda y medularmente suyo, el patrimonio espiritual de la humanidad entera sufre una pérdida irremediable. 